\title{
Quality perception and willingness to pay: The case of red wine with health-beneficial effects
}

\author{
Jelena Ruso ${ }^{1}$, Jovan Filipović1 ${ }^{1}$ Milica Maričić ${ }^{1 *}$, Vesna Spasojević-Brkić ${ }^{2}$ \\ ${ }^{1}$ University of Belgrade, Faculty of Organizational Sciences, Belgrade, Serbia; ${ }^{2}$ University of Belgrade, Faculty of \\ Mechanical engineering, Belgrade, Serbia
}

*Corresponding Author: Milica Maričić, Department of Operational Research and Statistics, University of Belgrade, Faculty of Organizational Sciences, Jove Ilića 154, Belgrade, Serbia, Email: milica.maricic@fon.bg.ac.rs

Received: 15 October 2020; Accepted: 14 February 2021; Published: 1 April 2021

(c) 2021 Codon Publications

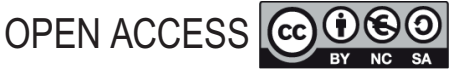

PAPER

\begin{abstract}
This paper attempts to identify consumers' preferences toward red wine quality cues and willingness to pay (WTP) for wine with health-beneficial effects, thus clarifying the complex process of purchasing habits and patterns. The data were analyzed using structural equation modeling. The findings from a case study conducted in Serbia show that consumer health-effect consciousness and household income are significant predictors of their WTP. On the other hand, health-conscious consumers are more inclined to intrinsic quality cues, while those who are willing to pay a higher price for a bottle of red wine are prone to extrinsic wine quality cues.
\end{abstract}

Keywords: consumer quality perception, red wine, structural equation modeling, willingness to pay, wine preferences

\section{Introduction}

The choice-making of wine is a difficult and complicated process since there is a diverse and vast range of wines available in the market (Agnoli et al., 2016). Accordingly, numerous papers aimed to segment and cluster the wine market (Caracciolo and Furno, 2020; $\mathrm{Hu}$ and Ruimei, 2019), and thus indicate the importance of diverse wine quality attributes in the overall consumer preference. Quality perception is seen as a mediator between product characteristics and consumer preferences (Steenkamp, 1989; Tomic et al., 2017). Consumer judgment about an entity's overall superiority (product, service, and process) is based on the cues of excellence (Lee and Hwang, 2016; Snoj et al. 2004). One of the biggest challenges for businesses and wine industry is to meet consumer requirements and the need to understand their decision-making when purchasing wine.

A extensive body of literature sheds light on the quality cues of wine (Rodrigues and Parr, 2018; Sáenz-Navajas et al., 2013; Verdú Jover et al. 2004). For example, Verdú Jover et al. (2004) observed consumer preferences through
15 red wine quality cues and divided them into extrinsic and intrinsic elements. Intrinsic cues are defined as inherent characteristics of wine, including taste, color, acidity, level of alcohol, etc. (Hu and Baldin, 2018; Valentin et al., 2016). On the other hand, extrinsic attributes are often associated with noninherent characteristics such as brand, price, and year of production, country of origin, grape variety, label, tradition, awards, and recommendation (Boncinelli et al., 2019; Lu et al., 2017; Sáenz-Navajas et al., 2013, 2016; Williamson et al. 2016). Verdú Jover et al. (2004) determined seven quality dimensions that contain the majority of aspects used in the 15 initial cues: origin, image, presentation, age, harvest, sensitivity, and acuteness of bouquet. Next, Jaeger et al. (2009) recognized 13 intrinsic and extrinsic purchasing decision-making wine cues such as award, brand, origin, grape variety, taste, recommendation, information presented on the label, alcohol level, etc. For instance, Heatherly et al. (2019) and Valentin et al. (2016) emphasized color as a strong intrinsic predictor of consumer preference. However, different research studies have indicated that extrinsic cues are becoming the main determinants of wine quality (Balestrini and Gamble, 2006; Reynolds et al., 2018). 
Besides quality cues related to hedonistic and social beliefs, consumer beliefs about the health benefits of wine are gradually becoming an important factor of purchase (Samoggia, 2016). Nowadays, health-conscious customers are looking for food and beverages that are not only nutritional but also have extraordinarily health benefits (Rathi, 2018). The health effects of wine were pointed at as far back as in ancient Greece and Rome (Fiore et al., 2019). Recent research has highlighted that red wine is considered a healthy drink (Chang et al., 2016; Vecchio et al., 2017), because it contains ingredients that support cardiovascular, neurodegenerative, and aging health, and reduce the risk of cancer, diabetes, Parkinson's, and Alzheimer's disease (Fiore et al., 2019; Krstonošić et al., 2019; Kuršvietienè et al., 2016; Liberale et al., 2019; Soares et al., 2015). Nevertheless, customer opinions differ. Chinese consumers tend to drink more red wine for its potential health benefits, whereas Australian consumers are less likely to rate wine as a healthy product (Yoo et al., 2013). The same belief about the positive health effects of wine was noticed among young adults in Portugal (Patrícia Silva et al., 2014). However, Thach and Olsen (2006) revealed that a minority of youth in the United States highlighted the health-beneficial effects as the main reason for wine-consuming. Conversely, Agnoli et al. (2016) conclude that novice consumers fail to completely recognize the beneficial effects of wine on health (Mueller and Szolnoki, 2012). Regarding wine purchasing reasons, Bazzani et al. (2019) acknowledge that health-oriented customers prefer extrinsic cues referring to quality assurance information (marked on the label) such as hand-picked grapes, sustainable product certifications, and unfiltered wine. In the research conducted by Cavaliere et al. (2016), however, customers are keener on reading nutrition information on the bottle label. Furthermore, Bazzani et al. (2019) and Martin-Moreno et al. (2013) also found out that health-conscious consumers have an aversion toward a higher percentage of alcohol content. Most of the previously mentioned studies highlight red wine benefits, show that most people are aware of the curative effects of this wine, and indicate that health-oriented consumers pay more attention to information provided on label.

The positive consumer perception of wine quality and willingness to pay (WTP) can be associated with health-enhancing wines (Samoggia, 2016), organic wines (Jorge et al., 2020), sustainable wines (Sellers-Rubio and Nicolau-Gonzalbez, 2016), or Old World producer wines (Giacomarra et al., 2020). Researchers often point to consumers' attitudes toward tasty, healthy, and eco-friendly food that influence their shopping behavior (Jorge et al., 2020). For example, consumers in Spain are willing to pay for resveratrol-enriched wine (Barreiro-Hurlé et al., 2008), while it was also found that health-oriented consumers are willing to pay more for health-enhancing wine
(Bisson et al., 2002; Higgins and Llanos, 2015; Samoggia, 2016). Therefore, high values of health-related substances in wine tend to lead to increased consumption of the particular wine type (Fiore et al., 2019). Finally, Samoggia (2016) observed that consumers, who doubted the favorable effect of wine on one's health, failed to perceive the positive relation between higher price and the health properties of wine.

Scientific literature has frequently examined the above-mentioned topics. To the best of our knowledge, however, few authors have jointly observed relationship between consumer consciousness of health-beneficial effects of wine, quality cues preferences, and WTP. Hence, the paper attempts to create and verify a conceptual model which explores consumers' perception regarding the following constructs: Intrinsic Wine Quality Perception (IWQP), Extrinsic Wine Quality Perception (EWQP), Health Effect Consciousness (HEC), and WTP, while also considering Monthly Household Income (MHI). The model tested on wine consumers in Serbia aimed to improve the conceptual models on the topic devised so far and fill in the literature gaps related to the habits and patterns of consumption of red wine.

Serbia is one of the major producers and consumers of grapes and wines in Southeast Europe (Radovanović et al., 2019). According to Statistical Report on World Vitiviniculture (OIV, 2019), Serbia ranks 30th in the world in terms of wine consumption with 1.1 million hectolitres. Also, in 2018, Serbia imported \$31.6 million worth of wine (Workman, 2019), that is, $0.1 \%$ of the world's total worth. The growth of wine market in Serbia thus presents a challenge for marketing and quality management professionals. Proper understanding of the consumer quality perception would therefore help retailers, producers, and supplying organizations to successfully design their marketing strategies for evolving markets in order to have a significant competitive advantage.

The next section of this paper provides a detailed overview of the proposed conceptual model and the related hypotheses. The results and discussion are given in the third section, while the concluding remarks are outlined in section four.

\section{Methodology}

\section{The proposed conceptual model}

In our research, we attempted to broaden some of the current conceptual models for exploring the factors that impact the consumer behavior of red wine. The proposed conceptual model consists of the following four 
constructs: HEC, EWQP, IWQP, and WTP, and also takes into account MHI.

HEC construct points to the degree of consumer awareness expressed through the attitudinal questions on health issues and the impact of red wine on human health (Appendix 1). Another construct, EWQP, indicates the level of importance of extrinsic quality in consumer's wine purchasing decision, including tradition, price, awards, recommendation, grape variety, brand, label, year of production, and country of origin. By investigating purchase intention, Huang et al. (2018) stated that wine lovers prefer to use extrinsic characteristics. So, the first hypothesis we test in our study is as follows:

H1. Consumer consciousness of red wine health effect influences extrinsic wine quality perception.

The third construct, IWQP, points to the degree of importance of intrinsic quality in consumer wine purchasing decision such as flavor, health ingredients, wine color, additives, percentage of alcohol, and acidity. According to Bazzani et al. (2019), Cavaliere et al. (2016), and Martin-Moreno et al. (2013), consumers who are conscious of the positive effects of wine on their health are more inclined to pay attention to intrinsic cues. Therefore, the next hypothesis we propose is as follows:

\section{H2. Consumer consciousness of red wine health effect} influences intrinsic wine quality perception.

The fourth construct, WTP, is determined by questions linked to the amount of money buyers are willing to spend on a bottle of red wine. Some of the researchers observed the effects of extrinsic cues on the willingness to pay (Lee et al., 2018; Nowak et al., 2006; Veale and Quester, 2009). For instance, Nowak et al. (2006) indicate that consumers are willing to pay more for a famous wine brand. Hence, following is our third hypothesis:

\section{H3. Consumer willingness to pay influences extrinsic wine quality perception.}

Generally, some studies have found that consumers are more willing to pay for intrinsic quality cues such as nutritional contents or freshness (Balineau, 2018). The same conclusion is observed in a study conducted by Barreiro-Hurlé et al. (2008) and Gabrielyan et al. (2014). Our next hypothesis is as follows:

H4. Consumer willingness to pay influences intrinsic wine quality perception.

Even though some studies failed to find a significant relationship between health attitudes and willingness to buy, most authors discovered a positive relationship between
WTP and consumer consciousness (Bisson et al., 2002; Higgins and Llanos, 2015; Samoggia, 2016). Accordingly, following is our next hypothesis:

\section{H5. Consumer consciousness of red wine health effect influences consumer willingness to pay.}

High willingness to pay for a bottle of wine may also relate to a higher household income (Hofmann et al., 2018; Sogari et al., 2016). Research indicates that the respondents with a higher household income are ready to pay more for a bottle of wine and turn to premium wine (Camillo, 2012; Onofri et al., 2015). Consequently, following is the final hypothesis:

\section{H6. Monthly household income influences consumer willingness to pay.}

The proposed conceptual model is graphically presented in Figure 1. For more details on the questions used to measure each construct, see Appendix 1.

\section{Data analysis}

To test the validity of the proposed conceptual model, we opted for the structural equation modeling (SEM). The SEM analysis is a multivariate statistical analysis based on the principles of factor analysis and regression or path analysis (Hox and Bechger, 1998; Kline, 2005). On one side, SEM reduces the dimensionality of the observed phenomenon, while on the other it provides insights on the relationship between the newly formed latent variables or constructs. Taking into account the benefits of the SEM analysis and the clear theoretical concept it is based on, this analysis has become a vastly applied approach for representing dependency in multivariate data (Kline, 2005).

So far, the SEM analysis has been conducted in the research field of wine consumption. For example, Vilela et al. (2018) used SEM to explore how the sensory profile of the respondent impacted his/her observation of the wine aroma, mouth feel, and flavor for three different types of Portuguese wine. Pestar Bizjak et al. (2018) observed how respondents from two Slovenian wine regions perceived the value of wine through emotional-social dimension, quality-price, and terroir and the impact of regiocentrism. Further, Bianchi (2015) proposed a conceptual model of consumer brand loyalty based on wine knowledge, wine experience, wine brand satisfaction, wine brand trust, and wine brand loyalty, and tested this in Chile.

\section{The survey}

Inspiration for the items of a questionnaire came from Bruwer et al. (2002); Cholette and Castaldi (2005); 


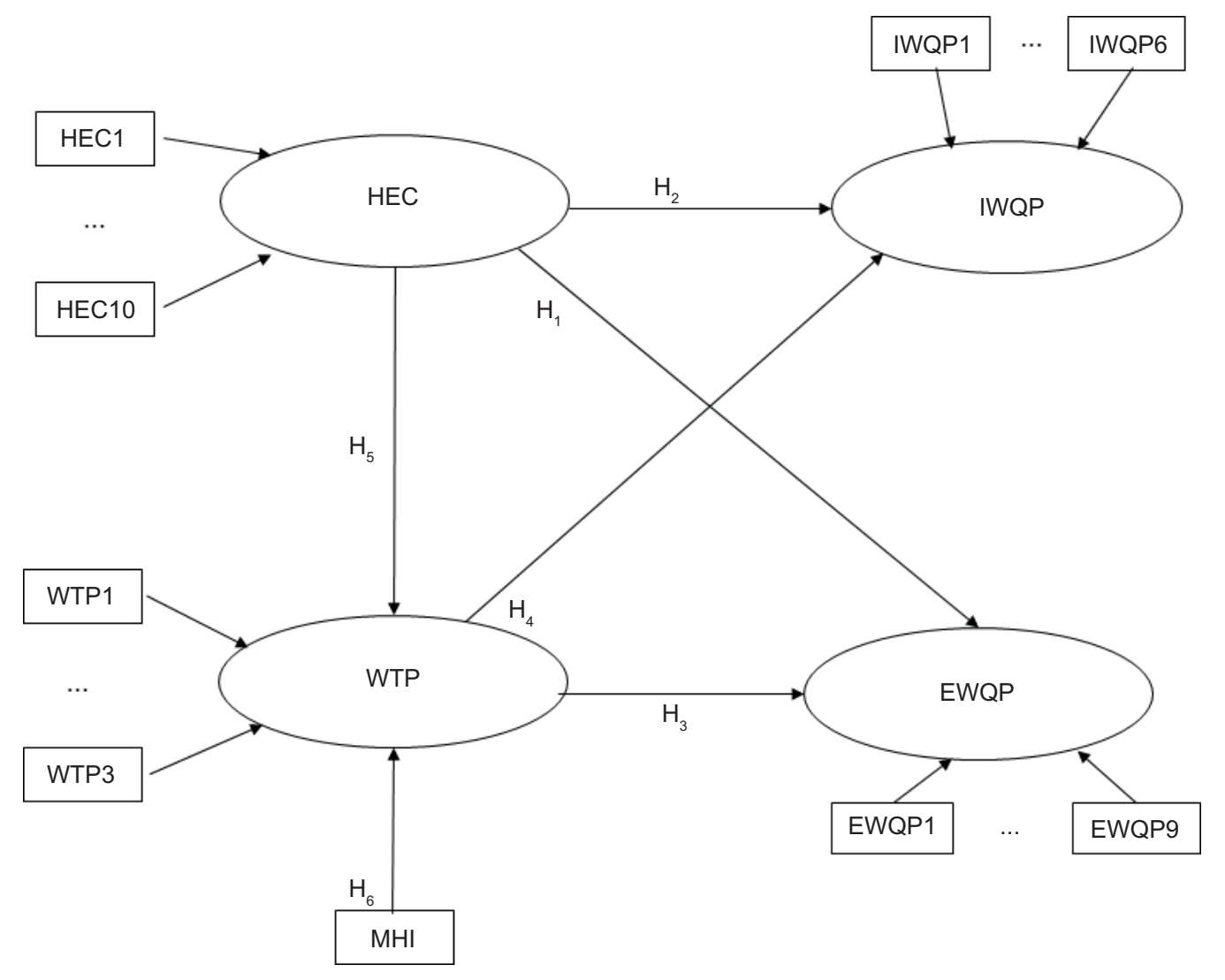

Figure 1. Conceptual model.

Johnson et al. (2017); Keller (2009); Lim et al. (2013); Sjostrom et al. (2016); Werdelmann (2014); and Yoo et al. (2013). The questionnaire was distributed online between September 2019 and January 2020. Some of the questions were adopted for the purpose of the study, while some scales were used in the original form. All the questions regarding respondents' opinions on red wine cues were measured on a 5-point Likert scale ranging from 1 (strongly disagree) to 5 (strongly agree). For more details on the questions used to measure each construct, and the obtained mean values and standard deviations (SD), see Appendix 1. The questionnaire was distributed on Facebook groups related to wine consumption and on LinkedIn. The questionnaire comprised the following five groups of questions: Demographic information, Habits of red wine consumption, Health characteristics, Price, and Quality perception. In the first section of the questionnaire, the respondents were asked some basic demographic information regarding gender, age, residence, highest completed degree, and household income. The rest of the questions were related to the frequency, quantity, occasions and place of consumption, and purchase of red wine, its characteristics, price, health effects, and perceptions of respondents about red wine consumption. Afterwards, statistical analysis using SPSS 25 and AMOS 22 was performed.

\section{Results and discussion}

\section{Sample characteristics}

A total of 605 responses were collected after closing the questionnaire. In order to obtain a sample of true wine consumers, we asked respondents whether they declare themselves as red wine consumers in the first place. In reply, 496 respondents $(81.9 \%)$ declared themselves as consumers of red wine, while the remaining 109 (18.1\%) responded in negative. The non-consumers of red wine were not eligible for our research, so their answers were removed from further analysis.

The sample consisted of 312 female respondents, who formed $62.9 \%$ of the sample, and 184 were male respondents (37.1\%). A slight disproportion in the respondents' gender was observed, but the same was also found in the work of Bruwer (2004). Most of the respondents (64.7\%) are in the age group 18-32 years, followed by the age group 33-45 years $(24.8 \%)$. The remaining respondents were aged more than 46 years. This indicates that our sample comprised younger population, namely GenXers and Millennials. It is expected that GenXers would become the largest consumers of wine in 2021, while Millennials would take over in 2026 (Mcmillan, 2018). Accordingly, it 
is reasonable to focus on all these segments. Similar age distribution of respondents within a sample was found in wine consumption research conducted by Bruwer (2004) and Bruwer et al. (2012). Respondents mainly came from Serbia (73.2\%), followed by consumers from other countries of the region (Montenegro, Bosnia and Herzegovina, and Croatia). Taking a look at the highest educational degree, $51.0 \%$ of the respondents had a bachelor's degree, $22.4 \%$ had a master's degree, $15.7 \%$ completed high school, while $10.9 \%$ had PhD. We observed that the sample consisted of highly educated individuals, with $60.0 \%$ of surveyed millennials having at least a bachelor of science (BSc). This indicated that in this regard the sample was unbalanced. We believe that this occurred due to the sampling method used. Although this might be a limitation of the study, we believe that it would not distort the conclusions as we were observing healthenhanced wine which was more expensive and regarded as premium wine, which respondents with lower educational attainment and income did not often consume. Most respondents earned a monthly income between $€ 1000$ and $€ 2000$ (36.1\%), 35.1\% earned income below $€ 1000$, while the rest had a monthly income of above $€ 2000$. It was concluded that we covered a segment of the population which was young, educated, and had more than Serbia's average monthly income. Sample characteristics are provided in Table 1.

To provide additional insights on the consumers' attitudes toward the four explored constructs of the proposed model, we provide mean value and SD of each item of the constructs in Appendix 1.

Furthermore, we aimed to obtain insight on the respondents' attitudes and habits regarding consumption of red wine. Most of the respondents (32.7\%) were consuming red wine for 1-5 years, followed by those who had been consuming for 6-10 years (28.8\%). As for frequency of consumption of red wine, most of the respondents consumed it once every 2 months (38.3\%), followed by those who consumed it on a monthly basis $(19.4 \%)$ or once in a fortnight (16.3\%). As for purchasing habits, most respondents (32.3\%) consumed one to three bottles per year, followed by those who consumed over 10 bottles (27.4\%). On the other hand, $39.3 \%$ of the respondents buy one to three bottles a year as a gift. Half of the respondents $(50.8 \%)$ believed that the reasonable price of a red wine bottle is between $€ 5$ and $€ 10$, while $27.6 \%$ were ready to pay between $€ 10$ and $€ 40$. This suggests that a large percentage of our respondents had multiple years of moderate consumption and purchasing habits and were ready to pay for a good bottle of wine.

\section{SEM model}

The primary step in SEM analysis is to observe the internal consistency of the proposed latent variables. The
Table 1. Characteristics of the respondents who participated in the survey.

\begin{tabular}{lcc} 
Variable & Frequency & Proportion \\
\hline $\begin{array}{l}\text { Gender } \\
\text { Female }\end{array}$ & & \\
Male & 312 & $62.9 \%$ \\
Age group & 184 & $37.1 \%$ \\
18-32 & & \\
$33-45$ & 321 & $64.7 \%$ \\
$46-64$ & 123 & $24.8 \%$ \\
$65-75$ & 48 & $9.7 \%$ \\
Educational attainment & 4 & $0.8 \%$ \\
High School & & \\
BSc & 92 & $15.7 \%$ \\
MSc & 253 & $51.0 \%$ \\
PhD & 111 & $24.2 \%$ \\
Monthly household income & 54 & $10.9 \%$ \\
Less than $€ 1000$ & & \\
$€ 1000-2000$ & 174 & $35.1 \%$ \\
$€ 2000-3000$ & 179 & $36.1 \%$ \\
$€ 3000-4000$ & 51 & $10.2 \%$ \\
$€ 4000-5000$ & 34 & $6.9 \%$ \\
Over $€ 5000$ & 17 & $3.4 \%$ \\
\hline
\end{tabular}

most commonly used metric for internal consistency and scale reliability is Cronbach's alpha (Cronbach, 1951). The Cronbach's alpha provides a metric level up to which all the measured variables in a latent construct measure the same concept, and it takes values from 0 to 1 . The closer the Cronbach's alpha is to 1, the higher the internal consistency (Peterson, 1994). As reported by relevant literature, the acceptable levels of Cronbach's alpha are in the range of 0.70-0.95 (Tavakol and Dennick, 2011). Besides Cronbach's alpha, average variance extracted (AVE) and construct reliability are used (Fornell and Larcker, 1981). The closer these indices are to 1 , the better the internal consistency; thus, this shows that the scale is more reliable. The threshold for the acceptable level for AVE is above 0.5, while for composite reliability, it is above 0.7 (Fornell and Larcker, 1981; Wong, 2013).

The calculated Cronbach's alpha per latent variable and the number of items per scale are given in Table 2. As presented, the internal consistency ranges from 0.751 (WTP) to 0.984 (HEC). The composite reliability for all constructs is at the threshold of 0.7 or above. However, when it comes to AVE, EWQP's AVE is less than the threshold (0.447). Having in mind the obtained metrics of reliability and validity, we can conclude that the data are suitable for SEM analysis.

Additionally, we explored the normality of variables in the model, having in mind that the 
Table 2. Obtained Cronbach's alpha, average variance extracted (AVE), and composite reliability per construct and the number of items per construct.

\begin{tabular}{lllll} 
& HEC & IWQP & EWQP & WTP \\
\hline No. of items & 10 & 6 & 9 & 3 \\
Cronbach's alpha & 0.984 & 0.862 & 0.886 & 0.751 \\
AVE & 0.501 & 0.470 & 0.447 & 0.484 \\
Composite reliability & 0.904 & 0.841 & 0.876 & 0.697 \\
\hline
\end{tabular}

Note: HEC - Health Effect Consciousness; IWQP - Intrinsic Wine Quality Perception; EWQP - Extrinsic Wine Quality Perception; WTP - Willingness to Pay

non-normality might significantly impact the result of analysis. According to Muthén and Kaplan (1985), 'if most variables have univariate skewness and kurtosis in the range -1.0 to +1.0 , not much distortion is to be expected.' In our sample, out of 28 variables in the model, six proved to have issues with skewness and kurtosis in the range from -2 to 3 . Taking into account that just several variables expressed skewness and kurtosis out of the suggested range, we continued with the analysis (Hallow, 1985).

The initial model had relatively poor fit to the data (Chisquare $=2643.028, \mathrm{df}=372, P<0.000$, Root Mean Square Error of Approximation (RMSEA) $=0.111$, Comparative Fit Index $(\mathrm{CFI})=0.862$, Tucker-Lewis Index $(\mathrm{TLI})=$ 0.849). To evaluate the significance of the paths and indicators, we used critical ratios (C.R.). The value of C.R. above 1.96 or below -1.96 points out a two-sided significance at the 5\% level (Hox and Bechger, 1998). Paths between HEC and EWQP and between IWQP and WTP had a C.R. below the defined threshold, so they were removed from the model. Additionally, we used modification indices to fine-tune our model. The final model had relatively good fit to the data (Chi-square $=$ 1721.177, $\mathrm{df}=328, P<0.000, \mathrm{RMSEA}=0.092$, CFI $=$ 0.915 , TLI $=0.895)$. The detailed model assessment is given in Table 3.
Concerning the construct IWQP, it initially had two predictors, HEC and WTP. However, WTP proved to be statistically insignificant, which would mean that hypothesis H4 was not confirmed. The obtained standardized coefficient of the impact of HEC on IWQP was 0.776 , with C.R. $=12.888$, indicating that HEC significantly impacted IWQP and the impact was positive and medium in strength, taking into account that the standardized coefficient could take a value of $0-1$. This finding confirmed the assumption $\mathrm{H} 2$. The $R^{2}$ of this construct was 0.601 , meaning that one predictor explained $60.1 \%$ of the variability of IWQP, thus creating a solid model. These results showed that more health-conscious consumers valued more the intrinsic characteristic of wine quality (focusing on flavor, healthy ingredients, color, percentage of alcohol, additives, and acidity). The results were in accordance with the research done by Bazzani et al. (2019) and Martin-Moreno et al. (2013). The obtained result might be due to the fact that health-oriented consumers were more likely to undertake actions and behaviors that could contribute to their health improvement and thus pay more attention to the intrinsic quality of wine cues (Cavaliere et al., 2014).

Similar to IWQP, EWQP also initially had two predictors, HEC and WTP. In this case, HEC proved to be statistically insignificant, thus hypothesis $\mathrm{H} 1$ was not proved.

Table 3. Assessment of the model: construct, predictors, obtained unstandardized and standardized coefficients, C.R., $R^{2}$, and the decision on the related hypothesis.

\begin{tabular}{llcccrr} 
Construct & Predictors & UnStd. Coeff. & Std. Coeff. & C.R. & $R^{2}$ & Hypothesis \\
\hline \multirow{2}{*}{ IWQP } & HEC & 0.203 & 0.776 & 12.880 & 0.601 & H2-Approved \\
& WTP & & Not significant & & H4-Rejected \\
EWQP & HEC & & Not significant & & 0.613 & H1-Rejected \\
& WTP & 0.542 & 0.783 & 16.449 & H3-Approved \\
WTP & HEC & 0.710 & 0.975 & 33.908 & 0.998 & H5-Approved \\
& MHI & 0.124 & 0.221 & 13.202 & H6-Approved \\
\hline
\end{tabular}

Note: C.R. - Critical ratio, $R^{2}$ - R square, HEC - Health Effect Consciousness; IWQP - Intrinsic Wine Quality Perception; EWQP - Extrinsic Wine Quality Perception; WTP - Willingness to Pay; MHI - Monthly Household Income 
The obtained standardized coefficient of the impact of WTP on EWQP was 0.783 with C.R. = 16.449, indicating that WTP significantly impacted EWQP statistically and that the impact was positive and medium in strength. The $R^{2}$ of this construct was 0.613 , meaning that one predictor explained $61.3 \%$ of the variability of EWQP, thus creating a solid model. The results suggested that consumers who were more willing to pay a higher price for a bottle of red wine and its health effect were more inclined to extrinsic wine cues such as price, year of production, country of origin, brand image, grape variety, label, tradition, recommendation, and award. Correspondingly, hypothesis H3 hypothesis, about a positive impact of WTP on EWQP, was also confirmed. A similar relation was observed by Lee et al. (2018) and Veale and Quester (2009).

The construct WTP had two predictors, HEC and MHI, and both proved to be statistically significant. In the final model, HEC and MHI had a statistically significant positive impact with respective standardized coefficients of 0.975 and 0.221. MHI was left in the model, although its impact was weak as it was statistically significant and the goal was to obtain a good measurement model (Allen et al., 2019; Milenković et al., 2019). The $R^{2}$ of this construct was $99.8 \%$, indicating that the two predictors explained a high percentage of variability of WTP. As in other research on wine consumption (Bisson et al., 2002; Higgins and Llanos, 2015; Samoggia, 2016), the findings indicated that health-conscious consumers were willing to pay more for a bottle of red wine as well as for health-enhancing wine. In corroboration of the previous claims made by Hofmann et al. (2018), Hu and Ruimei (2019), Onofri et al. (2015), and Sogari et al. (2016), results included the observation that respondents with higher MHI seemed to have higher WTP. In other words, people who earned more were willing to pay more for a bottle of red wine. Hence, we can say that hypotheses $\mathrm{H} 5$ and $\mathrm{H} 6$ were proved.

The graphical interpretation of the results and the final model are given in Figure 2.

\section{Conclusion}

The way a user views the quality of a product is closely related to his/her needs and requirements. These needs include not only the physical benefit of the product but also the one that relates to the image a user creates of himself/herself for the use of a specific brand and all other aspects of the benefits of the delivered product that are considered valuable. Furthermore, a user's perception

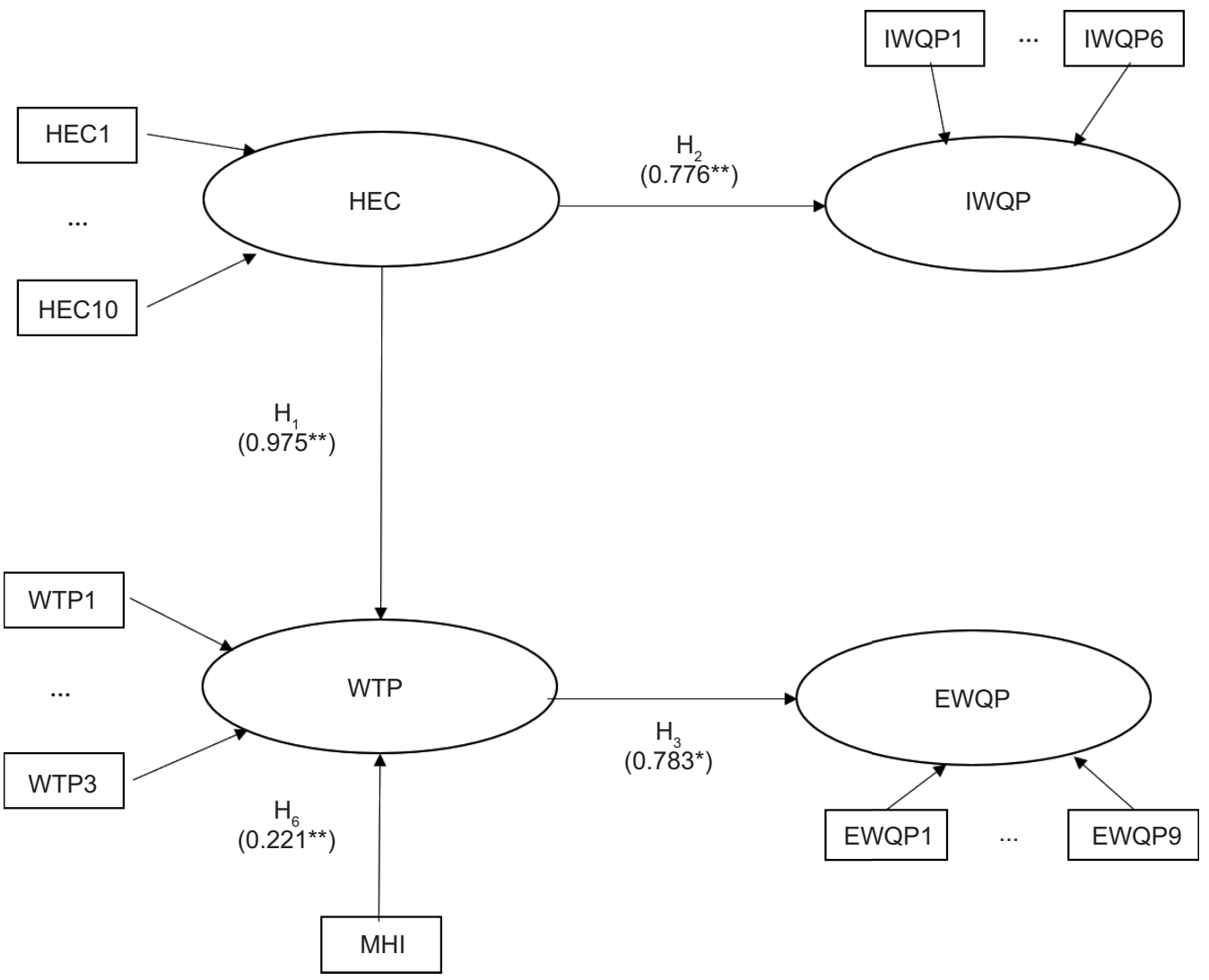

Figure 2. Final conceptual model. ${ }^{* *} P<0.01$. 
of a product quality and its characteristics can influence the creation of a different marketing strategy for the same product.

The purpose of this paper was to create and verify a conceptual model which explores consumers' perception of red wine. The design of this study imparted significant insights into the issue of consumer preference in the case of red wine. The research covered a segment of population that was young, educated, with an above-the-average Serbian monthly income, and having multiple years of moderate consumption and purchasing habits and was ready to pay for a good bottle of wine. By employing SEM, we developed a conceptual model that pointed to different influences between five constructs: IWQP, EWQP, HEC, WTP, and MHI. The findings established that the initial model was changed, and four out of six set hypotheses were confirmed. After the analysis, it was found that consumer quality perception has two predictors-HEC and WTP. Health-conscious consumers were keen on evaluating intrinsic quality cues, while respondents who would pay a higher price for red wine inclined to extrinsic quality cues. Moreover, health-oriented respondents and those with higher MHI depicted that they were willing to pay a higher price for red wine as well as for health-enhanced red wine.

Our study provided useful insights, but it was not without limitations. First, the sample size was a limitation of the study. Although we had almost 700 respondents after closing the survey, a larger sample could have been expected as we were exploring wine consumption, a product of mass consumption. As a remedy, we suggest a larger sample based solely on Serbian consumers or even a regional study in several Balkan countries in the future studies. Another possible limitation, as elaborated above, might be the sample structure, which was biased toward highly educated individuals. Also, convenience sampling based solely on the individuals who had Facebook and LinkedIn accounts limited our ability to generalise the findings of the study. This suggests that different approach to sampling could be taken in the future studies.

The obtained knowledge had a number of theoretical and managerial implications. Given that Serbia represents an evolving wine market, understanding consumers' willingness, consciousness, and perception could significantly contribute to the understanding of purchasing behavior. This would further help companies develop an appropriate marketing strategy and prepare for the Balkan market.

The future research should be directed toward revealing premium wines preferences, including tasting, and/ or must focus on older population. A larger number of respondents from the Balkan region would allow for a comparative analysis, thus significantly improving the quality of the result. Also, another possible direction of the study could be the extension of the conceptual model by including new constructs such as wine knowledge, wine experience, or purchase intention (Bianchi, 2015).

The paper provided important information for policy makers to identify barriers, develop rules, policies, and initiatives, as well as labeling schemes to engage consumers in sustainable consumption of wines with health benefits. Our findings could benefit companies, wineries, and managers who plan to enter the growing wine market in Serbia and the Balkans. We believe that the proposed conceptual model for exploring the relationship between quality perceptions and willingness to pay would initiate further research on both factors that affected consumer decision-making process when purchasing red wine and the future improvements of the conceptual models regarding this topic.

\section{Acknowledgment}

This paper presented research funded by the Innovation Fund from the budget of the Republic of Serbia from the division of the Ministry of Education, Science and Technological Development, through the Serbia Competitiveness and Jobs Project (loan agreement with the World Bank), Grant No. 50138.

\section{Conflict of interest}

There are no conflicts of interest. The authors of this research strictly followed all ethical guidelines provided by the University of Belgrade.

\section{References}

Agnoli, L., Capitello, R. and Begalli, D. 2016. Behind intention and behaviour: factors influencing wine consumption in a novice market. Brit Food J. 118:660-678. https://doi.org/10.1108/ BFJ-05-2015-0181

Allen, J., Eboli, L., Forciniti, C., Mazzulla, G. and Ortúzar, J. de D. 2019. The role of critical incidents and involvement in transit satisfaction and loyalty. Transp Policy. 75:57-69. https://doi. org/10.1016/j.tranpol.2019.01.005

Balestrini, P. and Gamble, P. 2006. Country-of-origin effects on Chinese wine consumers. Brit Food J. 108:396-412. https://doi. org/10.1108/00070700610661367

Balineau, G. 2018. Engel curves for fair trade consumption and development perspectives for producers: evidence from data on real fairtrade purchases. J Dev Stud. 55:894-916. https://doi.org/ 10.1080/00220388.2018.1499894

Barreiro-Hurlé, J., Colombo, S. and Cantos-Villar, E. 2008. Is there a market for functional wines? Consumer preferences 
and willingness to pay for resveratrol-enriched red wine. Food Qual Prefer. 19:360-371. https://doi.org/10.1016/j. foodqual.2007.11.004

Bazzani, C., Capitello, R., Ricci, E.C., Scarpa, R. and Begalli, D. 2019. Nutritional knowledge and health consciousness: do they affect consumer wine choices? Evidence from a survey in Italy. Nutrients. 12:84. https://doi.org/10.3390/nu12010084.

Bianchi, C. 2015. Consumer brand loyalty in the Chilean wine industry. J. Food Prod. Mark. 21:442-460. https://doi.org/10.108 0/10454446.2014.885859

Bisson, L.F., Waterhouse, A.L., Ebeler, S.E., Walker, M.A. and Lapsley, J.T. 2002. The present and future of the international wine industry. Nature. 418:696-699. https://doi.org/10.1038/ nature01018

Boncinelli, F., Dominici, A., Gerini, F. and Marone, E. 2019. Consumers wine preferences according to purchase occasion: personal consumption and gift-giving. Food Qual Prefer. 71:270-278. https://doi.org/10.1016/j.foodqual.2018.07.013

Bruwer, J. 2004. The love affair of generation-X consumers with the winery tasting rooms. Aust NZ Grapegrow Winemak. 49:19-24.

Bruwer, J., Lesschaeve, I. and Campbell, B.L. 2012. Consumption dynamics and demographics of Canadian wine consumers: retailing insights from the tasting room channel. J Retail Consum Serv. 19:45-58. https://doi.org/10.1016/j.jretconser.2011.08.008

Bruwer, J., Li, E. and Reid, M. 2002. Segmentation of the Australian wine market using a wine-related lifestyle approach. J Wine Res. 13:217-242. https://doi.org/10.1080/0957126022000046510

Camillo, A.A. 2012. A strategic investigation of the determinants of wine consumption in China. Int J Wine Bus Res. 24:68-92. https://doi.org/10.1108/17511061211213792

Caracciolo, F. and Furno, M. 2020. Hedonic functions, heterogeneous consumers, and wine market segmentation. J Agr Resour Econ. 45:299-316. https://doi.org/10.22004/ag.econ.302456.

Cavaliere, A., De Marchi, E. and Banterle, A. 2014. Healthyunhealthy weight and time preference. Is there an association? An analysis through a consumer survey. Appetite. 83:135-143. https://doi.org/10.1016/j.appet.2014.08.011

Cavaliere, A., De Marchi, E. and Banterle, A. 2016. Does consumer health-orientation affect the use of nutrition facts panel and claims? An empirical analysis in Italy. Food Qual Prefer. 54:110116. https://doi.org/10.1016/j.foodqual.2016.07.008

Chang, K.J., Thach, M.L. and Olsen, J. 2016. Wine and health perceptions: exploring the impact of gender, age and ethnicity on consumer perceptions of wine and health. Wine Econ Policy. 5:105-113. https://doi.org/10.1016/j.wep.2016.09.001

Cholette, S. and Castaldi, R. 2005. Analyzing the US retail wine market using price and consumer segmentation models (referred). Available at: http://online.sfsu.edu/cholette/public_research/ Sonoma-Segmentation.pdf (Access 21/12/2020).

Cronbach, L.J. 1951. Coefficient alpha and the internal structure of tests. Psychometrika. 16:297-334. https://doi.org/10.1007/ BF02310555

Fiore, M., Alaimo, L.S. and Chkhartishvil, N. 2019. The amazing bond among wine consumption, health and hedonistic well-being. Brit Food J. 122:2707-2723. https://doi.org/10.1108/ BFJ-05-2019-0344.
Fornell, C. and Larcker, D.F. 1981. Evaluating structural equation models with unobservable variables and measurement error. J Marketing Res. 18:39-50. https://doi.org/10.2307/3150980; https://doi.org/10.1177/002224378101800104.

Gabrielyan, G., McCluskey, J.J., Marsh, T.L. and Ross, C.F. 2014. Willingness to pay for sensory attributes in beer. Agric Resour Econ Rev. 43:125-139. https://doi.org/10.1017/ S1068280500006948

Giacomarra, M., Galati, A., Crescimanno, M. and Vrontis, D. 2020. Geographical cues: evidences from new and old world countries' wine consumers. Brit Food J. 122:1252-1267. https://doi. org/10.1108/BFJ-08-2019-0580

Hallow, L.L. 1985. Behavior of some elliptical theory estimators with non-normality data in a covariance structures framework: a Monte Carlo study. Unpublished doctoral dissertation, University of California, Los Angeles.

Heatherly, M., Dein, M., Munafo, J.P. and Luckett, C.R. 2019. Crossmodal correspondence between color, shapes, and wine odors. Food Qual Prefer. 71:395-405. https://doi.org/10.1016/j. foodqual.2018.08.019

Higgins, L.M., and Llanos, E. 2015. A healthy indulgence? Wine consumers and the health benefits of wine. Wine Econ. Policy. 4:3-11. https://doi.org/10.1016/j.wep.2015.01.001

Hofmann, J., Jung, F., Wiacek, C., Braun, P.G., Luck-Sikorski, C. and Riedel-Heller, S.G. 2018. Functional foods with cardioprotective effects. An analysis of willingness to pay in the German general population. Ernahrungs Umschau. 65:54-63.

Hox, J.J. and Bechger, T.M. 1998. An introduction to structural equation modelling. Familiy Sci Rev. 11:354-373.

Hu, L. and Baldin, A. 2018. The country of origin effect: a hedonic price analysis of the Chinese wine market. Brit Food J. 120:12641279. https://doi.org/10.1108/BFJ-02-2017-0121

$\mathrm{Hu}$, Y. and Ruimei, W. 2019. A clustered-based segmentation of Chinese wine consumers by means of kernal fuzzy c-means. Ital J Food Sci. 31:764-781.

Huang, L., Bai, L., Zhang, X. and Gong, S. 2018. Re-understanding the antecedents of functional foods purchase: mediating effect of purchase attitude and moderating effect of food neophobia. Food Qual Prefer. 73:266-275. https://doi.org/10.1016/j. foodqual.2018.11.001

International Organisation of Vine and Wine (OIV). 2019. Report on the world vitivinicultural situation. OIV, Paris, France. Available at: http://www.oiv.int/en/oiv-life/oiv-2019-report-on-the-world-vitivinicultural-situation (accessed 18 April 2020).

Jaeger, S.R., Danaher, P.J. and Brodie, R.J. 2009. Wine purchase decisions and consumption behaviours: insights from a probability sample drawn in Auckland, New Zealand. Food Qual Prefer. 20:312-319. https://doi.org/10.1016/j.foodqual.2009.02.003

Johnson, T.E., Danner, L. and Bastian, S.E.P. 2017. Consumer segmentation methods for the wine market. In "Reference Module in Food Science 2017”. Arnout R.H. (Ed.). 1-6. Elsevier. https:// doi.org/10.1016/b978-0-08-100596-5.21419-4.

Jorge, E., Lopez-Valeiras, E. and Gonzalez-Sanchez, M.B. 2020. The role of attitudes and tolerance of ambiguity in explaining consumers' willingness to pay for organic wine. J. Clean. Prod. 257:1-12. https://doi.org/10.1016/j.jclepro.2020.120601 
Keller, K.L. 2009. Managing the growth tradeoff: challenges and opportunities in luxury branding. J Brand Manag. 16:290-301. https://doi.org/10.1057/bm.2008.47

Kline, R.B. 2005. Principles and practice of structural equation modeling, 2nd edition, Guilford Press, New York, NY.

Krstonošić, M.A., Cvejić Hogervorst, J., Torović, L., Puškaš, V., Miljić, U., Mikulić, M. and Bukarica, L.G. 2019. Influence of 4 years of ageing on some phenolic compounds in red wines. Acta Aliment. 48:449-456. https://doi.org/10.1556/066.2019.48.4.6

Kuršvietienè, L., Stanevičienė, I., Mongirdienė, A. and Bernatonienè, J. 2016. Multiplicity of effects and health benefits of resveratrol. Medicina. 52:148-155. https://doi.org/10.1016/j. medici.2016.03.003

Lee, H.J. and Hwang, J. 2016. The driving role of consumers' perceived credence attributes in organic food purchase decisions: a comparison of two groups of consumers. Food Qual Prefer. 54:141-151. https://doi.org/10.1016/j.foodqual.2016.07.011

Lee, W.F., Gartner, W.C., Song, H., Marlowe, B., Choi, J.W. and Jamiyansuren, B. 2018. Effect of extrinsic cues on willingness to pay of wine. Brit Food J. 120:2582-2598. https://doi.org/10.1108/ bfj-01-2017-0041.

Liberale, L., Bonaventura, A., Montecucco, F., Dallegri, F. and Carbone, F. 2019. Impact of red wine consumption on cardiovascular health. Curr Med Chem. 26:3542-3566. https://doi.org/ 10.2174/0929867324666170518100606

Lim, C.M., Kim, Y., and Runyan, R. 2013. Segmenting luxe-bargain shoppers using a fuzzy clustering method. Int J Retail Distrib Manag. 41:848-868. https://doi.org/10.1108/IJRDM-01-2013-0012

Lu, L., Rahman, I. and Chi, C. 2017. Ready to embrace genetically modified wines? The role of knowledge exposure and intrinsic wine attributes. Cornell Hosp. Q. 58:23-38. https://doi. org/10.1177/1938965516629775

Martin-Moreno, J.M., Harris, M.E., Breda, J., Moller, L., AlfonsoSanchez, J.L. and Gorgojo, L. 2013. Enhanced labelling on alcoholic drinks: reviewing the evidence to guide alcohol policy. Eur. J. Public Health. 23:1082-1087. https://doi.org/10.1093/eurpub/ ckt046

McMillan, R. 2018. Wine report: state of the wine industry 2018. Silicon Valley Bank. Available at: https://www.svb.com/wine-report. (accessed 29 April 2020)

Milenković, M., Glavić, D. and Maričić, M. 2019. Determining factors affecting congestion pricing acceptability. Transp Policy. 82:58-74. https://doi.org/10.1016/j.tranpol.2019.08.004

Mueller, L.S. and Szolnoki, G. 2012. Market price differentials for food packaging characteristics. Food Qual Prefer. 25:171-182. https://doi.org/10.1016/j.foodqual.2012.02.009

Muthén, B. and Kaplan, D. 1985. A comparison of methodologies for the factor analysis of non-normal Likert variables. Br. J. Math. Stat. Psychol. 38(1):171-189. https://doi.org/10.1111/j.2044-8317.1985. tb00832.x

Nowak, L., Thach, L. and Olsen, J.E. 2006. Wowing the millennials: creating brand equity in the wine industry. J. Prod. Brand. Manag. 15:316-323. https://doi.org/10.1108/10610420610685712

Onofri, L., Boatto, V. and Bianco, A.D. 2015. Who likes it 'sparkling'? An empirical analysis of Prosecco consumers' profile. Agric. Food Econ. 3:1-15. https://doi.org/10.1186/s40100-014-0026-x
Patrícia Silva, A., Figueiredo, I., Hogg, T. and Sottomayor, M. 2014. Young adults and wine consumption, a qualitative application of the theory of planned behaviour. Brit Food J. 116:832-848. https://doi.org/10.1108/BFJ-05-2012-0114

Pestar Bizjak, S., Hristov, H., Košmerl, T. and Kuhar, A. 2018. Influence of consumer regiocentrism on perceived value of wine. Brit Food J. 120:33-43. https://doi.org/10.1108/ BFJ-03-2017-0181

Peterson, R.A. 1994. A meta-analysis of Cronbach's coefficient alpha. J. Consum. Res. 21:381-391. https://doi.org/10.1086/209405

Radovanović, V.N., Andjelković, M., Arsić, B., Radovanović, A. and Gojković-Bukarica, L. 2019. Cost-effective ultrasonic extraction of bioactive polyphenols from vine and wine waste in Serbia. South African J. Enol. Vitic. 40:1-9. 10.21548/40-2-3215. https:// doi.org/10.21548/40-2-3215

Rathi, V. 2018. Herbal wine: a review. J Nutr Weight Loss. 3:1-7. https://doi.org/10.35248/2593-9793.18.3.113

Reynolds, D., Rahman, I., Bernard, S. and Holbrook, A. 2018. What effect does wine bottle closure type have on perceptions of wine attributes? Int. J. Hosp. Manag. 75:171-178. https://doi. org/10.1016/j.ijhm.2018.05.023

Rodrigues, H. and Parr, W.V. 2018. Contribution of cross-cultural studies to understanding wine appreciation: a review. Food Res. 115:251-258. Int. https://doi.org/10.1016/j.foodres.2018.09.008.

Sáenz-Navajas, M.P., Ballester, J., Fernández-Zurbano, P., Ferreira, V., Peyron, D. and Valentin, D. 2016. Wine quality perception: a sensory point of view. In: Moreno-Arribas, M.V and Bartolomé Suáldea, B. (eds.), Wine safety, consumer preference, and human health, Springer, Cham, Switzerland pp. 119-138. https://doi.org/10.1007/978-3-319-24514-0_6

Sáenz-Navajas, M.P., Campo, E., Sutan, A., Ballester, J. and Valentin, D. 2013. Perception of wine quality according to extrinsic cues: the case of Burgundy wine consumers. Food Qual Prefer. 27:44-53. https://doi.org/10.1016/j.foodqual.2012.06.006 Samoggia, A. 2016. Wine and health: faraway concepts? Brit Food J. 118:946-960. https://doi.org/10.1108/BFJ-07-2015-0267

Sellers-Rubio, R. and Nicolau-Gonzalbez, J.L. 2016. Estimating the willingness to pay for a sustainable wine using a Heckit model. Wine Econ. Policy. 5:96-104. https://doi.org/10.1016/j. wep.2016.09.002

Sjostrom, T., Corsi, A.M. and Lockshin, L. 2016. What characterises luxury products? A study across three product categories. Int. J. Wine Bus. Res. 28:76-95. https://doi.org/10.1108/ IJWBR-05-2015-0017

Snoj, B., PisnikKorda, A. and Mumel, D. 2004. The relationships among perceived quality, perceived risk and perceived product value. J. Prod. Brand. Manag. 13:156-167. https://doi. org/10.1108/10610420410538050

Soares, S., Brandão, E., Mateus, N. and de Freitas, V. 2015. Sensorial properties of red wine polyphenols: astringency and bitterness. Crit Rev Food Sci Nutr. 57:937-948. https://doi.org/10.1080/10 408398.2014.9464.68

Sogari, G., Mora, C. and Menozzi, D. 2016. Sustainable wine labeling: a framework for definition and consumers' perception. Agric. Sci. Procedia. 8:58-64. https://doi.org/10.1016/j. aaspro.2016.02.008 
Steenkamp, J.-B.E.M. 1989. Product quality. An investigation into the concept and how it is perceived by consumers. Van Gorcum, Assen, the Netherlands.

Tavakol, M. and Dennick, R. 2011. Making sense of Cronbach's alpha. Int. J. Med. Educ. 2:53-55. https://doi.org/10.5116/ ijme.4.dfb.8dfd

Thach, E.C. and Olsen, J.E. 2006. Market segment analysis to target young adult wine drinkers. Agribusiness. 22:307-322. https:// doi.org/10.1002/agr.20088

Tomic, B., Spasojević Brkić, V., Karapetrovic, S., Pokrajac, S., Milanović, D.D., Babić, B. and Djurdjevic, T. 2017. Organizational culture, quality improvement tools and methodologies, and business performance of a supply chain. Proc Inst Mech Eng B J Eng Manuf. 231:2430-2442. https://doi. org/10.1177/0954405416629100

Valentin, D., Parr, W.V., Peyron, D., Grose, C. and Ballester, J. 2016. Colour as a driver of Pinot noir wine quality judgments: an investigation involving French and New Zealand wine professionals. Food Qual Prefer. 48:251-261. https://doi.org/10.1016/j. foodqual.2015.10.003

Veale, R. and Quester, P. 2009. Do consumer expectations match experience? Predicting the influence of price and country of origin on perceptions of product quality. Int Bus Rev. 18:134-144. https://doi.org/10.1016/j.ibusrev.2009.01.004

Vecchio, R., Decordi, G., Grésillon, L., Gugenberger, C., Mahéo, M. and Jourjon, F. 2017. European consumers' perception of moderate wine consumption on health. Wine Econ. Policy. 6:14-22. https://doi.org/10.1016/j.wep.2017.04.001
Verdú Jover, A.J., Lloréns Montes, F.J. and Fuentes Fuentes, M. del M. 2004. Measuring perceptions of quality in food products: the case of red wine. Food Qual Prefer. 15:453-469. https://doi. org/10.1016/j.foodqual.2003.08.002

Vilela, A., Marques, C. and Correia, E. 2018. Structural equation modelling (SEM) applied to sensory profile of Vinho Verde monovarietal wines. Food Res. Int. 111:650-660. https://doi. org/10.1016/j.foodres.2018.05.077

Werdelmann, T. 2014. Quality and value creation on the premium wine market. J Appl Leadership Manag. 3:47-72.

Williamson, P.O., Lockshin, L., Francis, I.L. and Mueller Loose, S. 2016. Influencing consumer choice: short and medium term effect of country of origin information on wine choice. Food Qual Prefer. 51:89-99. https://doi.org/10.1016/j.foodqual.2016.02.018

Wong, K.K.K. 2013. Partial least squares structural equation modeling (PLS-SEM) techniques using smart PLS. Marketing Bull. 24:1-32.

Workman, D. 2019. Top wine importing countries, world's top exporters. Available at: http://www.worldstopexports.com/ top-wine-importing-countries/. (accessed 22 September 2020)

Yoo, Y.J., Saliba, A.J. and Prenzler, P.D. 2010. Should red wine be considered a functional food? Compr Rev Food Sci F. 9:530-551. https://doi.org/10.1111/j.1541-4337.2010.00125.x

Yoo, Y.J., Saliba, A.J., MacDonald, J.B., Prenzler, P.D. and Ryan, D. 2013. A cross-cultural study of wine consumers with respect to health benefits of wine. Food Qual Prefer. 28:531-538. https:// doi.org/10.1016/j.foodqual.2013.01.001 
Ruso J et al.

\section{Appendix 1}

Willingness to pay

\begin{tabular}{llll} 
Item & Mean & SD & Source \\
\hline 1. An acceptable price for a bottle of red wine at retail & 2.20 & 0.869 & Cholette and Castaldi (2005) \\
2. Reasonable price of red wine with curative effects & 1.82 & 2.644 & Yoo et al. (2010) \\
3. I would pay more for health-enhanced red wine & 3.17 & 2.253 & \\
\hline
\end{tabular}

\section{Health effects consciousness}

\begin{tabular}{llll} 
Item & Mean & SD & Source \\
\hline 4. Red wine can slow down the aging process and extend human life & 3.33 & 2.024 & Yoo et al. (2013) \\
5. Red wine can reduce the risk of certain diseases (cardiovascular and meta- & 3.52 & 2.047 \\
bolic diseases and cancer) & & \\
6. Red wine can cure certain diseases & 2.61 & 2.130 \\
7. I think, red wine is a healthy alcoholic beverage & 3.45 & 2.221 \\
8. Red wine has better health properties than other alcoholic beverage & 3.67 & 2.227 \\
9. It is important to limit the amount of alcohol you consume & 4.35 & 2.258 \\
10. I understand how much alcohol is considered healthy & 3.66 & 2.335 \\
11. I know what moderate drinking is & 4.22 & 2.430 \\
12. Red wine has more health-enhancing properties & 3.56 & 2.453 \\
13. I would drink more red wine if I thought it was healthy for me & 3.24 & 2.574
\end{tabular}

Intrinsic wine quality perception

\begin{tabular}{llll} 
Item & Mean & SD & Source \\
\hline 14. Flavor & 4.43 & 1.104 & Bruwer et al. (2002); \\
15. Health ingredients & 3.51 & 1.239 & Werdelmann (2014); Yoo et al. \\
16. Color of wine & 3.47 & 1.391 & \\
17. Alcohol (\%) & 3.15 & 1.461 & \\
18. Additives & 3.08 & 1.569 & \\
19. Acidity & 3.43 & 1.540 & \\
\hline
\end{tabular}

\section{Extrinsic wine quality perception}

\begin{tabular}{llll} 
Item & Mean & SD & Source \\
\hline 20. Price & 3.80 & 1.116 & Bruwer et al. (2002); \\
21. Year of production & 3.05 & 1.268 & Werdelmann (2014); Yoo \\
et al. (2013) \\
22. Country of origin & 3.17 & 1.342 & \\
23. Brand image & 2.93 & 1.328 \\
24. Grape variety & 3.28 & 1.414 \\
25. Label & 2.91 & 1.159 \\
26. Tradition & 3.21 & 1.568 \\
27. Recommendation & 3.95 & 1.500 \\
28. Awards & 3.08 & 1.627 \\
\hline
\end{tabular}

